and other publicity announcing the time and place. You are also urged to attend the BIS Think Tank Committee meeting on Sunday morning, January
7, from 9:00-11:00 a.m., if you have any ideas to pass on to the committee.

\title{
Installing a local area compact disk
}

\section{network}

\author{
By Joan Carey \\ Computer Services Coordinator \\ Brandeis University
}

and Virginia Massey-Burzio

Head of Reader Services

Brandeis University

\section{Patron acceptance of databases on CD-ROM justifies their installation and expense.}

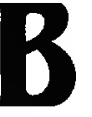

randeis is a small, highly competitive research university. Its two libraries, the Main and Science Libraries, support an undergraduate population of 3,500 students and a graduate student population of approximately 900 . Recently the Main Library (Social Sciences and Humanities) was selected as a test site for the installation of SilverPlatter's MultiPlatter local area network (LAN). The overall reaction to the network has been very enthusiastic.

\section{The CD-ROM network}

On January 26, 1989, the SilverPlatter MultiPlatter system was installed. This is a slightly modified version of CD-Net, developed by Meridian Data Corporation. The basis for the network is Novell Netware zunning over Thin Wire Ethernet. The network server consists of five stacked drives with a 286 processor. Because the server does not have a hard disk drive, access software is mounted on each individual workstation. Our installation was unique in many ways. We were the first to run
MultiPlatter on an Ethernet (Boston College has a Token Ring LAN). We also were the first to use non-uniform hardware. Our current hardware configuration consists of five workstations: one IBM XT, one IBM PC with a hardcard, two Zenith AT compatibles, and one Wyse M310 workstation. The two Zenith stations are equipped with color monitors. Four of these stations are located in the public area near the reference desk. The fifth station, located at the reference desk, is used for a variety of additional functions which include: dialup access to online search vendors like Dialog and BRS; access to other Boston-area online public catalogs; connecting to our campus-wide network; and word processing. All stations are connected to Hewlett-Packard "Thinkjet" printers.

Another unusual aspect of this project was the number and variety of compact disk (CD) products installed. We have ten disks from five different vendors, with only five slots in our server. Therefore, reference staff must "swap" disks on a regular basis. Patrons choose the disk they wish to search from an AutoMenu Screen. A command informs 
them if the disk they seek is not mounted on the system. We have also had to install the software for five different vendors in each computer.

Currently we own:

SilverPlatter: Psychological Abstracts-Current, Psychological Abstracts-Archive, Monthly Catalog of Government Publications.

Wilson: Social Sciences Index, Library Literature, MLA Bibliography, Readers' Guide to Periodical Literature.

PAIS: Public Affairs Information Service.

UMI: Newspaper Abstracts.

MicroSoft: Bookshelf.

For about one month after the initial installation the system worked well. Then there was gradually increasing trouble with "freezes." The term "freeze" is used to describe times when one or more of our workstations would not function. None of the keys worked when pressed. Sometimes rebooting the individual workstation would solve the problem, but more often than not, all stations would freeze simultaneously and only resetting the MultiPlatter server would solve the problem. Sometimes error messages would appear on the monitors, but not always. Initially freezes were a couple of times per day, but soon they were several times an hour. By mid-March we were virtually at a standstill. We isolated and tracked a variety of problems, suspecting either our workstation hardware or one of the disk products to be the cause. When no recognizable pattern emerged, SilverPlatter decided to replace the server. The new server was installed on March 30, 1989. There have been no more "freeze" problems, but several months later one drive failed. It was a straightforward type of problem and the drive was replaced by SilverPlatter.

With the current configuration, the system is at capacity as far as number of drives because of the memory limitations in each station. Wilson products, in particular, require large amounts of memory. If we continue to run Wilson products, we cannot presently add additional "towers" to our MultiPlatter configuration. A tower is the basic MultiPlatter unit. Each tower holds five or six drives. Towers are chained together to add additional drives to the system. Because of the way Wilson has implemented MicroSoft Extensions, memory becomes an issue when networking these products. This issue has been discussed with SilverPlatter and they are currently working on a solution to this problem for their system.

Adding monthly and quarterly updates is relatively easy. However, because vendors have made their software so easy to install, they have assumed that minimum documentation is sufficient. Consequently, adequate documentation is not always available for those wanting to manipulate files. File name analyses are needed and default settings should be more clearly defined.

At Brandeis, with the current configuration, the library is limited to keeping certain products in certain drives in the MultiPlatter tower. This again appears to be a result of variations in the way different vendors have implemented MicroSoft Extensions. With some products a particular drive in the MultiPlatter tower must be permanently assigned. This limits flexibility because the product must always be resident in the particular drive to be accessed. This is somewhat inconvenient when swapping disks, but certainly not a major difficulty. If we had one drive for each disk, disk location would be inconsequential.

Another, much larger problem is created by the fact that patrons must enter and exit a variety of different software products on the same system. However, this in no way dampens the intense enthusiasm patrons have for the system. One particular issue the reference staff would like addressed by Wilson is that of entering and exiting Wilson databases. It is very easy to inadvertently end up in the wrong database. Another important need is a front-end product that would allow for searching different vendors' products with a single search software.

\section{Training}

For over a year, SilverPlatter's PsycLit disks have been available for patron searching. Therefore, it was assumed that our staff would be able to search the other SilverPlatter product acquired, the GPO Monthly Catalog. However, they were apprehensive at the thought of having to learn four more search software products and seven new databases at the same time. What proved to be effective was setting up a single drive station in the Reference Workroom. This allowed members of the staff to experiment with each product at their leisure and in a comfortable environment. Nevertheless, we soon realized that more than just access to the products was needed. As a result, "AntiAnxiety Sessions" were implemented. The core reference staff met in small groups to examine each product. A new product was selected each week and time was set aside to discuss and demonstrate its use. This was a valuable forum for venting frustrations. A leader was assigned to guide each session. The sessions were informal and repeated as necessary.

A decision was made to introduce products to the public in a staggered fashion. In this way undue pressure was not placed on staff to become "experts" at every database before allowing patrons to use them. We were still thinking in terms of online searching where cost requires the librarian to be thoroughly prepared before beginning to search. We have since learned that not only are most 
patrons satisfied with the simplest of searches, but that it is quite acceptable for us to try a variety of approaches and to check the manual when necessary as we assist our patrons.

Another and more difficult training issue was and continues to be that of training non-core reference librarians and graduate student assistants. We are assisted at the reference desk by as many as 8-10 graduate students, several librarians from other departments and library assistants.

Skill-based checklists were created. These checklists itemize the skills reference desk personnel need to have, from booting a computer to finding names in a particular database. Staff filled them out and then received small group and individualized training according to the needs indicated by the checklists. This was extremely laborintensive. Much reinforcement was needed by the core staff. This support group has understandably had the toughest time coping with the new technologies.

\section{Patron training}

Because our patrons like to be independent, most of our instruction is at point of use and in small groups. However, patrons seem to require a core 15-minute period of instructional time to begin even simple searching. Patrons are enthusiastic and anxious to use the $\mathrm{CD}$ databases, but the products do require training. We have created introductory documentation for database use, but more work needs to be done in this area. Vendors could really help reference librarians by providing on-disk tutorials and instructional guides to their products. SilverPlatter is the only vendor who has created good documentation for users, both in print and online.

\section{Data collection and performance}

Over these first six months, use of the network has been very heavy. During the busy times of the semester it was not unusual to have all stations occupied all day. However, we were unable to collect accurate use statistics. In June 1989 SilverPlatter installed a prototype of a statistics collection module. This package will allow us to track usage by day, week, month and year. Users can be tracked by database and statistics like average minutes per session can be obtained. This is a brand new package, currently limited to individual workstations, but we are looking forward to network-wide collection capabilities.

No significant levels of degradation in search time when several users are searching the same database have been noticed. What has been seen are major differences in search time because of the variety of hardware used. The Zenith machines are noticeably faster than any of the others while the $\mathrm{PC}$ with a hardcard is very slow. Patrons remain largely unaware of these differences. Once they have experienced CD searching, they don't like to return to the use of print indexes.

\section{Impact on reference service}

There have been several noticeable effects on reference service. The most gratifying has been the public relations value for the library. Our patrons have made it clear that we have given them something that they value. A marked decrease, almost $30 \%$, in online searching has been noted. In an academic environment, patrons seldom pay for searches out of their own pocket unless they have a grant or special funding for search purposes. While many of our online search patrons have moved over to $C D$ searching, many who were unable to afford online searching have embraced these "free" databases. Undergraduates make up a large part of this new group.

When a library provides a good service, it naturally creates an increased demand. Patrons want more and more CDs. Humanities scholars (especially in history and music) are clamoring for a product in their disciplines. Many users are asking about the availability of full-text of the indexed articles. Some have also requested dial-up access from home, office, or dorm room. A natural next step from the library's point of view is an expanded network to connect different CDs between libraries on campus.

While we are pleased by this new technology and hope to continue to expand, there have been a couple of issues on the down side. One is the effect on the workload of the reference staff. As mentioned above, patrons need 15 minutes of introduction to basic search techniques. Originally we assumed that the time spent teaching someone how to use a CD would be about the same amount of time spent on teaching users the use of a print index. The additional work associated with the CDs was not anticipated, especially in a network setting. With a print index, a user looks up one term, or phrase or name at a time; with a CD several terms can be combined, thus the user needs to understand basic search strategies.

Librarians have also had to spend valuable professional time engaged in routine low-level tasks such as replacing paper and changing ink. A second issue of concern is the high cost of network licensing fees. PsycLit has charged the library this fee for next year's subscription. If all the vendors follow this trend, libraries might not be able to afford to support or expand CD access for patrons. The price of print indexes are often based on the size of the library and its budget. This would seem to be a more acceptable approach. 


\section{Conclusion}

In summary, our $\mathrm{CD}$ network has been a tremendous success, but it has forced us to address the issues of what services can be realistically provided and what services must be reduced or eliminated. Over the past ten years more and more services have been added without appreciable staff increases. Because professional positions are expensive, it usually takes years to add just one position, and we are now creating a new reference model with a changing role for reference librarians. This new role has the potential to eliminate the reference desk as we now know it. Last year we added a
Hypercard Information Station ${ }^{1}$ which has made a significant impact in lowering the number of directional questions asked. We are investigating how electronic technology can further assist us in serving our patrons and allow us to function more efficiently and effectively.

'Paul Carnahan, "Designing a Hypercard Information Station: Principles for Product Developing," in Computers in Libraries, 1989, 4th Annual Conference and Exhibition, Conference Proceedings, ed. Nancy Melin Nelson (Westport, Conn.: Meckler, 1989).

\section{Letters}

\section{Leadership}

\section{To the Editor:}

In a recent letter to C $\triangleleft R L$ News (October 1989, p.799), I inadvertently allowed a kingly error to pass through undetected. Freud, I'm sure, would have been delighted. In my letter I was arguing for the importance of making greater commitments to professional development and the importance of reading smart as one step to prepare for leadership. I noted that we all have a stake in the future and therefore must continue our commitment to career development, "...particularly of those who will someday assume the reigns of leadership." I must have been recalling with some nostalgia the days when directors reigned rather than assumed the reins of leadership, which is more typical today. Those who noticed the slip may have assumed I said what I meant.-Richard M. Dougherty, Editor, Journal of Academic Librarianship, University of Michigan.

\section{Chinese academic libraries}

To the Editor:

We read, with some interest, Susan Tsui's short report on academic libraries in China in the September 1989 issue (pp.662-64). Though it is obviously impossible to give a complete picture of academic libraries in a country as vast and diverse as China, there are several points in the article that deserve further comment.

First, though the author is basically correct in her figures for Chinese library salaries, it should be pointed out that in China the employer is responsible for providing a vast range of fringe benefits unheard of in North America. The most important of these is housing, which is provided at an ex- tremely low cost (about 10 yuan or $\$ 3.00$ per month) and extra payments are made for coal, oil, and food. Also, various levels of government provide coupons that allow citizens to purchase food at highly subsidized prices. Chinese academic salaries are certainly not high, but the bare figures provided by Tsui paint a bleaker picture than exists in reality.

The author also seems to judge the staffing of Chinese libraries by current North American standards. While it is true that many senior library staff in China do not have MLS or equivalent degrees, it is incorrect to think of these people as political appointments. There is a critical shortage of trained librarians in China, especially over 30 years of age, and it is not uncommon for other academic staff to be assigned to work in the library. Many of these people have been librarians for many years, while others have been assigned more recently in an attempt to fill the gap of staff in their middle years (35-50) caused by the disruptions of the Cultural Revolution. This appointment of non-librarians to library posts existed not so long ago in North America, and it is fair to point out that the Librarian of Congress is an eminent scholar rather than a trained librarian. As more librarians become available and the possibilities for staff mobility increase in China, this situation is expected to change.

In the health sciences, subject access to library collections is becoming the norm. The Medical Subject Headings (MeSH) have been translated into Chinese, and the Chinese Academy of Medical Sciences (the Chinese MEDLARS Center) is developing a MEDLARS-compatible database of Chinese-language citations. Though many Chinese libraries do continue to use classification, rather than subject headings, âs the key to their collections, most give several class numbers to each book. This system is not unique to China, though it may 